Article

\title{
Experimental Study on the Surface Properties of Nanoalumina-Filled Epoxy Resin Nanocomposites
}

\author{
Deesy Pinto ${ }^{1(\mathbb{D}, \text { Ana M. Amaro }}{ }^{2, *(\mathbb{D})}$ and Luís Bernardo ${ }^{3(\mathbb{C}}$ \\ 1 CQM-Centro de Química da Madeira, University of Madeira, Campus da Penteada, 9020-105 Funchal, \\ Portugal; deesy.pinto@staff.uma.pt \\ 2 CEMMPRE, Department of Mechanical Engineering, University of Coimbra, 3030-788 Coimbra, Portugal \\ 3 Department of Civil Engineering and Architecture, Centre of Materials and Building \\ Technologies (C-MADE), University of Beira Interior, 6201-001 Covilhã, Portugal; lfb@ubi.pt \\ * Correspondence: ana.amaro@dem.uc.pt
}

Received: 3 January 2020; Accepted: 18 January 2020; Published: 21 January 2020

check for

\begin{abstract}
This article presents an experimental study on the surface properties of epoxy resin nanocomposites (EPNCs) manufactured with a thermosetting epoxy resin (EP)-bisphenol A diglycidyl ether (BADGE)-2-[[4-[2-[4-(Oxiran-2-ylmethoxy)phenyl]propan-2-yl]phenoxy]methyl]oxirane) and filled with alumina nanoparticles (NPs). The NPs consist of pretreated (with a silane agent) alpha alumina with irregular shapes and a $100 \mathrm{~nm}$ maximum size. Three weight fractions of NPs were studied: 1,3 , and 5 wt. (\%). Two different epoxy (EP) resins were manufactured, one cured and postcured with bis (4-aminophenyl) methane (DDM); and another one cured with 3-dodec-2-enyloxolane-2,5-dione (DDSA) + 8-methyl-3a,4,7,7a-tetrahydro-4,7-methano-2-benzofuran-1,3-dione (MNA). The wettability and the surface roughness of the obtained EPNCs were studied through the measurement of contact angles and topographic images obtained with atomic force microscopy (AFM), respectively. Significant influence of both the loading of NPs and used curing agents was observed. EPNCs cured with DDM were shown to be hydrophobic for 0,1 , and $3 \mathrm{wt}$. (\%) and hydrophilic for $5 \mathrm{wt}$. (\%). Maximum surface roughness was observed for $5 \mathrm{wt}$. (\%). EPNCs cured with DDSA+MNA were shown to be hydrophilic for 0 and $1 \mathrm{wt}$. (\%) and hydrophobic for 3 and $5 \mathrm{wt}$. (\%). The surface roughness decreased as the weight fraction of NPs increased until $3 \mathrm{wt}$. (\%), and then increased for $5 \mathrm{wt}$. (\%).
\end{abstract}

Keywords: epoxy resin nanocomposites; nano-alumina; curing agents; contact angle; surface roughness

\section{Introduction}

Thermosetting epoxy resins (EP) systems have been widely used as matrices for composite materials in several industries (e.g., aircraft, automotive, aerospace, shipbuilding, and civil construction industries). In particular, they have been used for metal substitution in several engineering applications (e.g., electronic devices, textiles, and machinery) and also as base materials for wear-resistant coating, adhesives, and advanced fibrous polymeric composites (PCs), among others [1-4].

In spite of their excellent performances, EPs have some drawbacks, such as brittle failure (because plastic deformation is constrained [5]), low toughness (weak resistance to crack initiation and propagation), low flow, high coefficient of linear thermal expansion, shrinkage, low thermal conductivity, and high sensitivity to cracks, which highly limit their application in some demanding fields [1-5]. In order to solve these drawbacks, a considerable amount of research has been carried out to modify EPs, for instance by changing their molecular structure to increase the crosslink density, leading to higher stiffness and strength [6]. In addition, the toughness of EPs can be improved by incorporating toughening agents such as liquids, rigid or hybrid rigid rubbery particles, or unreactive 
nano hardeners (i.e., nanoparticles (NPs)) at very low contents (usually described in terms of the weight fraction (wt. (\%)) or volume fraction (vol. (\%)) [2,3,7-11]. In recent years, special attention has been paid to EPs filled with NPs. These nanofillers (e.g., silicon dioxide $\left(\mathrm{SiO}_{2}\right)$ [12-14], titanium dioxide $\left(\mathrm{TiO}_{2}\right)[15,16]$, aluminum oxide $\left(\mathrm{Al}_{2} \mathrm{O}_{3}\right)$ [17-19]) are characterized by their specific shape and size (nanoscale), high surface areas, surface pretreatment, and the degree of dispersion into the EP matrix $[1,2,4,20,21]$.

In recent years, many studies have demonstrated that the inclusion of inorganic NPs into EPs has the capability to improve the stiffness, toughness, flexural modulus, fracture toughness, strength, hardness, and many other properties of the final PCs $[1-3,7,8]$, which are necessary in many engineering applications. These improvements are achieved without sacrificing the basic properties of EPs and with low percentages of NP loading [3,8,17,22-24]. Among the available NPs that have been studied and that can be used to reinforce EPs, alumina NPs constitute a good solution. The good results published in recent years, combined with the low cost of alumina NPs when compared to other NPs (for instance, alumina NPs are cheaper than titanium NPs), its high modulus (about $300 \mathrm{GPa}$ ), and high thermal resistance in comparison with others metal oxides NPs, show that functionalized alumina NPs are a viable and very promising solution to be used as nanoreinforcements for PCs $[1,2,4,8,22,24]$. Among the curing agents used as hardeners for EPs, some studies show that bis (4-aminophenyl) methane (DDM) [1,2,25-28] or 3-dodec-2-enyloxolane-2,5-dione (DDSA) + 8-methyl-3a,4,7,7a-tetrahydro-4,7-methano-2-benzofuran-1,3-dione (MNA) [28] are suitable for EP systems.

Both the physicochemical and topographical properties of surface materials are important for adhesion and coatings applications [29,30]. EP adhesives filled with NPs have also been recently investigated [20,21,31,32]. It was found that the inclusion of NPs can improve the wetting behavior, surface roughness, wear resistance, and shear strength, which are important properties for the resulting epoxy resin nanocomposites (EPNCs) to be used as adhesives or coatings.

The wettability of solid surfaces, including PCs, can be studied through the contact angle (CA) or the spreading area of a liquid over the surface. The contact angle, $\theta$, is the angle conventionally measured through the liquid, where a liquid-vapor interface meets a solid surface (see Figure 1). Smaller CAs or larger spreading areas imply higher wettability [20]. The CA on a rough surface of the same material, also called the apparent (or measured) contact angle $\theta^{*}$ (see Figure 1), is smaller. Therefore, the material is more wettable. This is because the surface area is increased due to roughness (the real surface area is higher than the geometrical surface area). Therefore, wettability and roughness are strongly related. The wetting characteristics of surface materials using functionalized NPs depend strongly on the NP distribution within the surface layers [21].

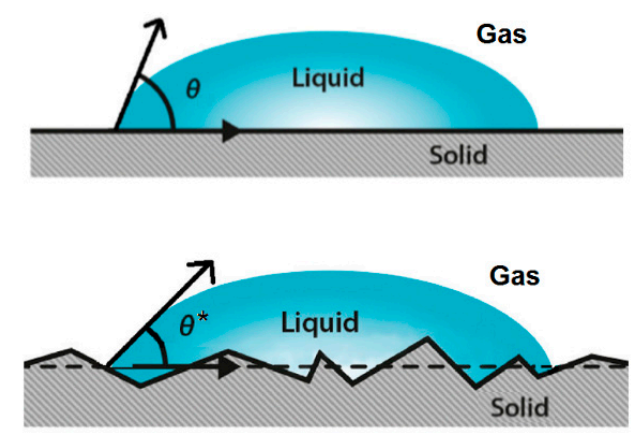

Figure 1. Definition of contact angle.

The surface roughness of PCs can be analyzed by atomic force microscopy (AFM), which is a relatively new technique used for the surface characterization of polymers. By using AFM, it is possible to obtain images of a non-conducting polymer surface and study its mechanical properties. Compared with other microscopy techniques, AFM does not involve any chemical etching, staining, 
or electron beam radiation, which can damage the polymer surface [6]. From the AFM topographic images, roughness coefficients can be computed, which represent the ratio of the real surface area to the geometrical surface area for identical external dimensions of the sample.

Wettability and roughness are important properties to be ensured for many applications, such as for painting and gluing components, for which the bonding to adhesives and coating substances are increased for wettable and roughened surfaces.

This article presents an experimental study on the wettability and the surface roughness of EPNCs manufactured with a thermosetting EP, which in turn is manufactured with two different curing agents (DDM and DDSA+MNA) and filled with functionalized alumina $\left(\mathrm{Al}_{2} \mathrm{O}_{3}\right) \mathrm{NPs}$ with different weight ratios, namely 1,3 , and $5 \mathrm{wt}$. (\%). To study the wettability, CAs were measured. To study the surface roughness, AFM topographic images were first obtained. Next, two amplitude parameters were evaluated, namely the arithmetic average roughness $\left(R_{a}\right)$ and the root mean square roughness $\left(R_{q}\right)$. These parameters were considered as measurements of the surface roughness, because AFM surface profiles can also be used to assess the nanofiller dispersion [32]. The obtained results, namely the mean values of CAs, the images of surface roughness from AFM, and the related amplitude parameters, are presented and discussed with respect to the influence of the NP loading. The results are differentiated for the two different thermosetting EP systems, which were obtained by using the two different curing agents (DDM and DDSA+MNA).

It should be noted that no previous studies focused on the wettability and surface roughness of EPNCs systems similar to those studied herein were found in the open literature. For this reason, the presented study can be considered original, and the obtained results are of great importance for future studies.

\section{Materials and Experimental Procedures}

\subsection{Raw Materials}

The used EP polymeric matrix was a 2-[[4-[2-[4-(Oxiran-2-ylmethoxy)phenyl]propan-2yl]phenoxy]methyl]oxirane (D.E.R. ${ }^{\mathrm{TM}}$ 332) based on bisphenol A diglycidyl ether (DGEBA, also known as BADGE). This thermosetting EP presents uniform performance, low viscosity, low chloride content, and light color. Two curing agents were used to obtain two different thermosetting EP systems: bis(4-aminophenyl)methane (DDM), and 3-dodec-2-enyloxolane-2,5-dione (DDSA) + 8-methyl-3a,4,7,7a-tetrahydro-4,7-methano-2-benzofuran-1,3-dione (MNA). For the EP cured with DDSA+MNA, the catalyst $N, N$-dimethyl-1-phenylmethanamine (BDMA) was applied during the curing reaction. All the raw chemicals were purchased from Sigma-Aldrich Co.

The alumina NPs, with $99.99 \%$ purity, were purchased from NanoshellTM LLC. The NPs are of irregular shape and present an average size less than $100 \mathrm{~nm}$. The specific surface area of the NPs is of $\sim 20 \mathrm{~m}^{2} / \mathrm{g}$. Figure $2 \mathrm{a}$ shows a micrograph of the as-received NPs obtained using electron scanning microscopy (SEM), using a FEI Quanta 400 FEG E SEM microscope. Figure $2 b$ shows a graph of the NP size distribution, as given by the supplier. The as-received alumina NPs incorporated a surface pretreatment (functionalized NPs) with a silane agent (3-Aminopropyl) triethoxysilane (APTES) to ensure high dispersion into the EP polymeric matrix. 


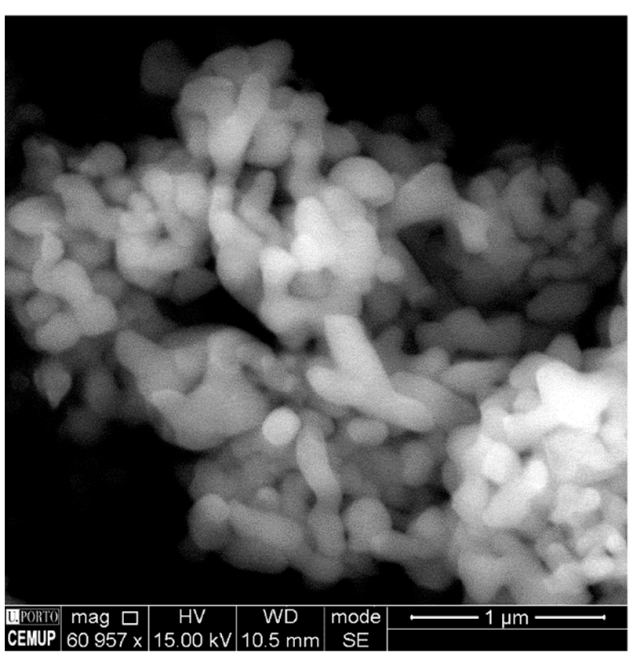

(a)

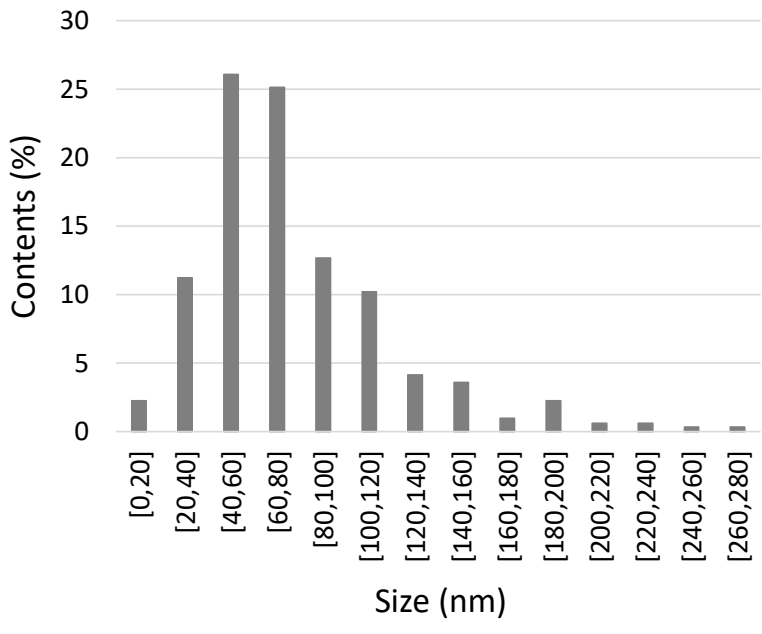

(b)

Figure 2. Alumina nanoparticles (NPs): (a) scanning electron microscopy (SEM) micrograph (x60957); (b) NP size distribution.

\subsection{Preparation of the Epoxy Resin Nanocomposites}

Two different manufacturing processes were performed because two different curing agents were used (DDM and DDSA+MNA) to produce the EP systems.

In the first manufacturing process (MP1), the stoichiometric amount of the thermoset system constituents was 3.51:1 of DER332/DDM, which was based on Bardella [33] and Belleri [34]. In the second manufacturing process (MP2), the chosen stoichiometric amount of the constituents was the same as recommended by Martinet et al. [35], namely 1:85:0.15:0.04 of DER332/DDSA/MNA/BDMA. In both manufacturing processes, the as-received functionalized alumina NPs were added into the mixture after the preheating of the EP matrix and before the addition of the curing agents. Three weight fractions of alumina NPs were considered for this study: 1, 3, and $5 \mathrm{wt}$. (\%). In addition, a neat EP system (0 wt. (\%)) was also manufactured for comparison. For both MP1 and MP2, the curing stage was carried out in an oven (Precision Scientific Napco vacuum oven model 5831) under vacuum conditions $(20 \mathrm{~mm} \mathrm{Hg})$ at $60^{\circ} \mathrm{C}$ for $24 \mathrm{~h}$ [33]. For MP2, an additional postcuring cycle with two interval time steps was performed on the cured samples: firstly for $2 \mathrm{~h}$ at $100^{\circ} \mathrm{C}$, and secondly for additional 3 $\mathrm{h}$ at $180^{\circ} \mathrm{C}$ [35].

The obtained EPNCs were allowed to cool at room temperature. After $24 \mathrm{~h}$, the samples were demolded and cut in order to obtain small geometrical samples for the measurements.

Additional details about the successive steps used in MP1 and MP2 to fabricate the EPNCs can be found in previous works from the authors $[1,2,28]$.

\subsection{Experimental Procedures}

CAs on EPNCs samples (without saturation) were measured with a contact angle tester using the sessile drop technique (DSA100 drop shape analyzer, Krüss GmbH [36]). Figure 1 illustrates the CA, $\theta$, of an ideal (smooth) surface [37]. In this study, the surface of the EPNCs samples where not polished and the apparent (measured) $\mathrm{CA}, \theta^{*}$, on a rough surface was obtained. The measurements were performed at room temperature and on dry samples. The probe liquid consisted of ultrapure water in a dosing syringe of $500 \mu \mathrm{L}$ with a needle $1.81 \mathrm{~mm}$ diameter. The drop volume ranged from 1 to $50 \mu \mathrm{L}$ on the solid surfaces of EPNC samples. The results were based on the average values of at least five replicates.

Topographic images of the EPNCs surfaces were obtained from AFM by using a Nanosurf FlexAFM System (Flex-Axiom). EPNC samples were cleaned beforehand by wiping the surface with $99 \%$ ethanol. Next, they were dried with a paper towel to remove the excess ethanol and subjected to a 
jet of compressed air until complete dryness. The measurements were performed with tapping mode (phase contrast) with a scanning rate between 1 and $2.5 \mathrm{~Hz}$ using a non-contact long reflex (NCLR) probe $(k=48 \mathrm{~N} / \mathrm{m}, f=190 \mathrm{kHz})$. For each EPNC sample, multiple images from areas of $10 \times 10 \mu \mathrm{m}^{2}$ were acquired at different locations.

Based the obtained topographic images of the EPNCs surfaces and using Gwyddion software to analyze AFM data, amplitude parameters were evaluated. These parameters characterize the surface based on the vertical deviations of the roughness map from the mean surface. Basically, they reduce all of the information from the topographic images to a single number. In this study, two amplitude parameters were evaluated [37]: the arithmetic average roughness $R_{a}$ (also called AA or CLA; Equation (1)) and the root mean square roughness $R_{q}$ (also called $R_{r m s}$; Equation (2)). These amplitude parameters are widely used in the literature.

$$
\begin{aligned}
R_{a} & =\frac{1}{n_{x} n_{y}} \sum_{i=1}^{n_{x}} \sum_{j=1}^{n_{y}}\left[Z(i, j)-Z_{a v e}\right] \\
R_{q} & =\sqrt{\frac{\sum_{i=1}^{n_{x}} \sum_{j=1}^{n_{y}}\left[Z(i, j)-Z_{a v e}\right]^{2}}{n_{x} n_{y}}}
\end{aligned}
$$

In the previous equations, the meaning of the parameters are the following ones: $i$ and $j$ corresponds to pixels in $x$ and $y$ direction, respectively, $n_{x}$ and $n_{y}$ are the maximum number of pixels in the two directions, $Z(i, j)$ represents the topography data for the surface (after specimen tilt-correction), and $Z_{\text {ave }}$ represents the height of the average surface.

\section{Results and Discussion}

\subsection{Contact Angle}

The apparent CA, $\theta^{*}$, was measured to evaluate the wettability of the EPNCs manufactured with a thermosetting epoxy resin hardened with two different curing agents and filled with different percentages of alumina NPs $(1,3$, and $5 \mathrm{wt}$. $(\%))$. The wettability is recognized satisfactory when the CA is less than $90^{\circ}$ [38] (the solid surface is considered to be hydrophobic if the CA is above $90^{\circ}$, and considered super-hydrophobic if the CA is above $120^{\circ}$ ), which means that the sample surface absorbs water. Figure 3 presents the obtained results for the apparent contact angle $\theta^{*}$.

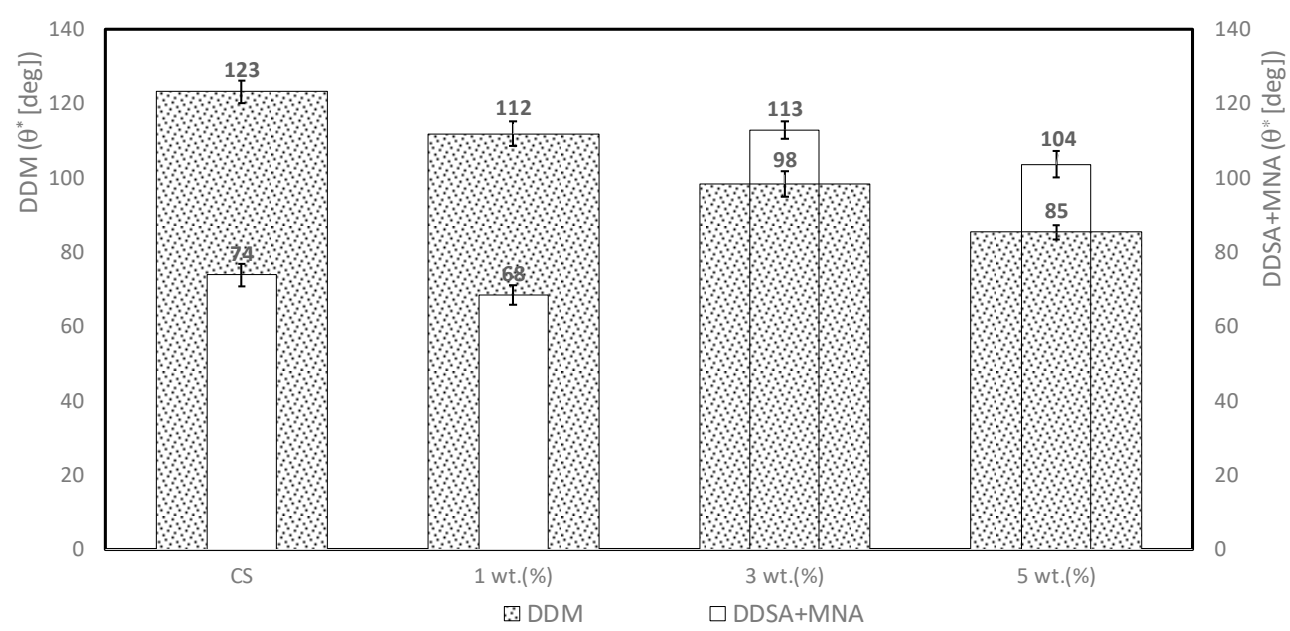

Figure 3. Apparent contact angles of epoxy resin nanocomposites (EPNCs) using bis(4-aminophenyl)methane (DDM) and 3-dodec-2-enyloxolane-2,5-dione (DDSA) + 8-methyl-3a,4,7,7a-tetrahydro-4,7-methano-2-benzofuran-1,3-dione (MNA) as hardeners. 
From Figure 3, it is possible to observe that the control sample (CS) (neat EP) using DDM as hardener is super-hydrophobic and displays CAs of about $123 \pm 3^{\circ}$. With the inclusion of alumina NPs, the hydrophobicity decreases by around $9 \%, 20 \%$, and $31 \%$ for 1, 3, and $5 \mathrm{wt}$. (\%), respectively, when compared with CS. Additionally, for 1 and 3 wt. (\%) samples, the EPNCs become hydrophobic, while for $5 \mathrm{wt}$. (\%) it turns hydrophilic. The opposite trend is detected for samples with DDSA+MNA hardener. In fact, CS using DDSA+MNA is observed to be hydrophilic with a CA of around $74 \pm 3^{\circ}$, and a slight difference is observed with the inclusion of $1 \mathrm{wt}$. (\%) alumina NPs. However, with further increase of the wt. (\%) NPs, the wettability decreases and the EPNCs become hydrophobic, which is in accordance with the observation of Hill et al. in 2019 [21]. From Figure 3, the major increase of about $53 \%$ compared with CS was observed for 3 wt. (\%) alumina NPs. For 5 wt. (\%) alumina NPs, the increase was about $40 \%$ when compared with CS. The decrease in the CA suggests that the wetting ability of the EPNCs increased [20]. According to Amaro et al. [1], better dispersion of NPs was achieved in the case of $1 \mathrm{wt}$. (\%) NPs, while at 3 and $5 \mathrm{wt}$. (\%), some NPs agglomerations were observed, which explains the increase of CA for such percentage loadings for the case with DDSA+MNA hardener. In fact, according to Radiom et al. [39], a higher NP concentration leads to a larger average particle size and induces higher CA. In the case of EPNCs with DDM as the hardener, better wetting ability was observed for $5 \mathrm{wt}$. (\%), while in the case of EPNCs with DDSA+MNA, a smaller CA was observed for $1 \mathrm{wt}$. (\%). When compared with CS, the EPNCs with DDSA+MNA containing $1 \mathrm{wt}$. (\%) alumina NPs showed the better CA. The observed decrease in the contact angle for the case of the DDM hardener could due to the type of matrix thermosetting system used. This is in accordance with Syakur et al. [40], who stated that the hydrophobicity of the surface is influenced by the type of matrix and the composition of the filler constituent.

\subsection{Surface Roughness}

The surface roughness of the EPNCs was studied through AFM. The arithmetic average roughness $R_{a}$ and the root mean square roughness $R_{q}$ were computed from multiple AFM topographical images for areas of $10 \times 10 \mu \mathrm{m}^{2}$ at different locations of the EPNC surface. The obtained results were averaged and the results are presented in Table 1. From this table, the trends observed for both amplitude parameters $\left(R_{a}\right.$ and $\left.R_{q}\right)$ are very similar. For this reason, in Figure 4 only the results related with $R_{a}$ are presented graphically.

Table 1. Roughness of EPNC surfaces.

\begin{tabular}{cccccccc}
\hline Sample & $w / w \boldsymbol{~}$ & $\boldsymbol{R}_{\boldsymbol{a}} \mathbf{n m}$ & St.Dev. $\mathbf{n m}$ & Coef. var. $\%$ & $\boldsymbol{R}_{\boldsymbol{q}} \mathbf{n m}$ & St.Dev. $\mathbf{n m}$ & Coef. var. $\%$ \\
\hline DDM_0 & 0 & 197.6 & 26.8 & 13.6 & 267.7 & 59.0 & 22.0 \\
\hline DDM_1 & 1 & 202.9 & 5.4 & 2.7 & 243.7 & 5.2 & 2.1 \\
\hline DDM_3 & 3 & 68.7 & 12.5 & 18.2 & 95.1 & 16.8 & 17.7 \\
\hline DDM_5 & 5 & 233.6 & 16.3 & 7.0 & 289.8 & 40.4 & 13.9 \\
\hline DDSA+MNA_0 & 0 & 331.6 & 56.7 & 17.1 & 487.1 & 120.8 & 24.8 \\
\hline DDSA+MNA_1 & 1 & 256.2 & 55.7 & 21.7 & 324.3 & 68.8 & 21.2 \\
\hline DDSA+MNA_3 & 3 & 17.4 & 2.7 & 15.5 & 21.6 & 3.6 & 16.7 \\
\hline DDSA+MNA_5 & 5 & 136.0 & 16.9 & 12.4 & 186.5 & 22.4 & 12.0 \\
\hline
\end{tabular}

St.Dev—Standard deviation; Coef. Var.-St.Dev./Value. 


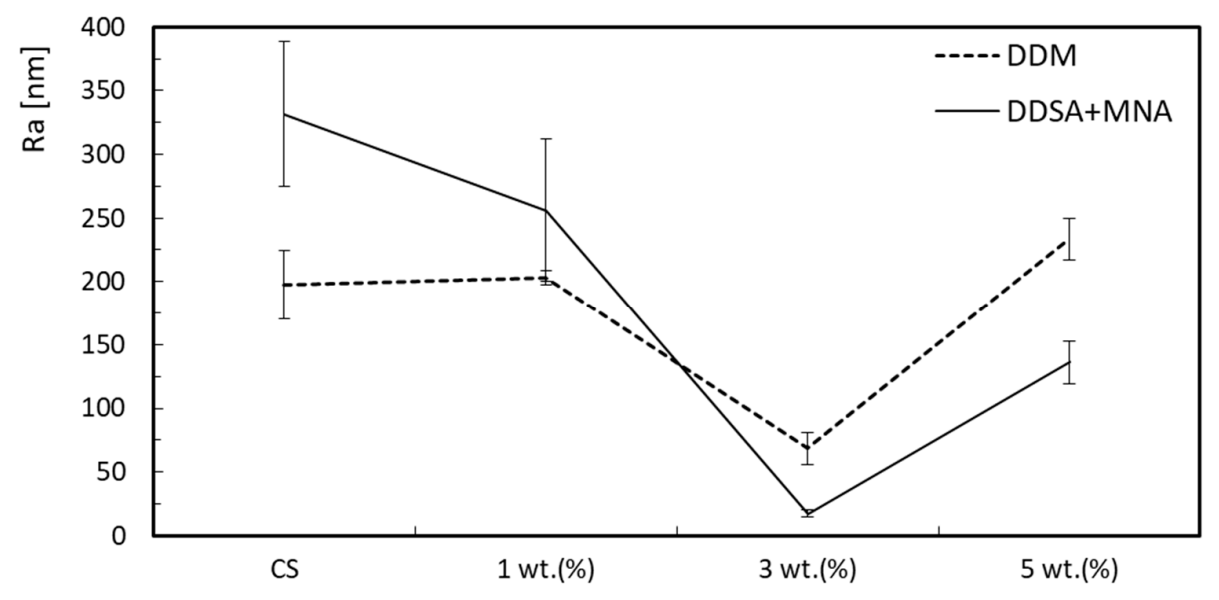

Figure 4. Arithmetic average roughness of EPNCs using DDM and DDSA+MNA as hardeners.

From Table 1 and Figure 4, it is possible to observe that for both hardeners (DDM and DDSA+MNA), a general decrease of the surface roughness $\left(R_{a}\right)$ is observed until $3 \mathrm{wt} .(\%)$ is reached, following by an increase for $5 \mathrm{wt}$. (\%). In the case of DDM hardener, the higher value for the surface roughness is obtained for $5 \mathrm{wt}$. \%, while for the case of DDSA+MNA hardener the higher value is obtained for the CS. From Table 1, it is observed that EPNCs with 3 wt. (\%) show decreases in $R_{a}\left(R_{q}\right)$ of around $65 \%$ and $64 \%$ (95\% and $96 \%)$ when compared with the CS with DDM and DDSA+MNA, respectively.

According to Figure 4, the EPNC surface that shows the highest average surface roughness is the CS; for both DDM and DDSA+MNA, the is the highest average surface roughness values are for super-hydrophobic and hydrophilic EPNCs, respectively. For DDM, the highest average surface roughness was for the surface corresponding to the EPNC with $5 \mathrm{wt}$. (\%) NPs, which was hydrophilic; and for EPNC this corresponded to the $1 \mathrm{wt}$. (\%) NP for the case of DDSA+MNA, which was also hydrophilic. For the DDM hardener, the results are in agreement with Uelzen and Muller [41], who stated that for smooth hydrophilic surfaces, the wettability is improved by roughening them, while for smooth hydrophobic surfaces the opposite is observed. In addition, CA will increase by roughening the surfaces. However, in this study and for EPNCs with DDSA+MNA, the opposite effect is observed. In fact, considering the hydrophobic surfaces for EPNCs with 3 and $5 \mathrm{wt}$. (\%) NPs, the contact angle decreases with the roughness. However, Uelzen and Muller [41] studied films, which could explain why the behavior is different. According to the author's knowledge, there are no studies concerning the study of CA and roughness for nanoalumina-filled epoxy resin nanocomposites.

Figures 5 and 6 present representative 2D and 3D AFM images for EPNCs cured with DDM and DDSA+MNA, respectively. From Figures 5 and 6, it is possible to observe some variability of the surface roughness of the studied EPNCs on the selected regions. However, the influence in the roughness results is not very high, since the coefficients of variation presented in Table 1 are generally below $20 \%$. 

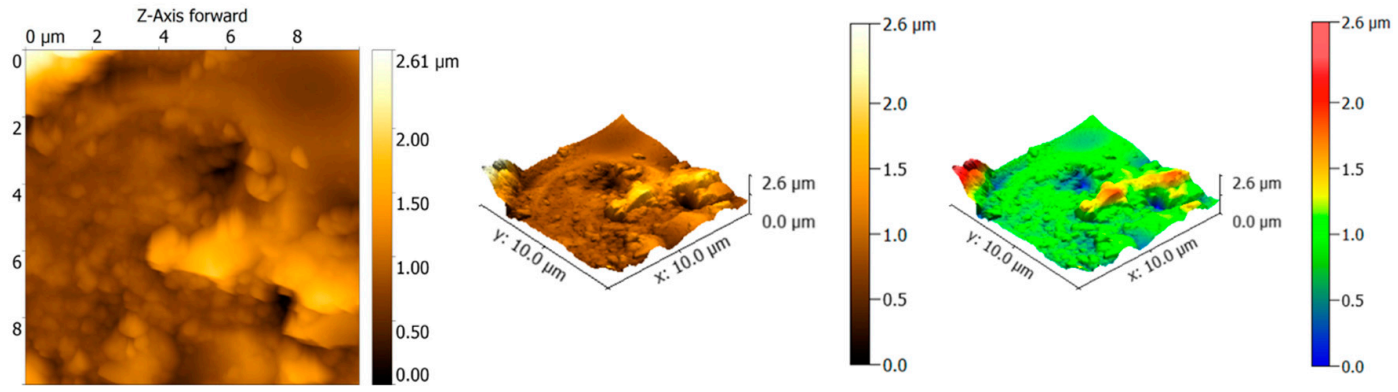

(a)
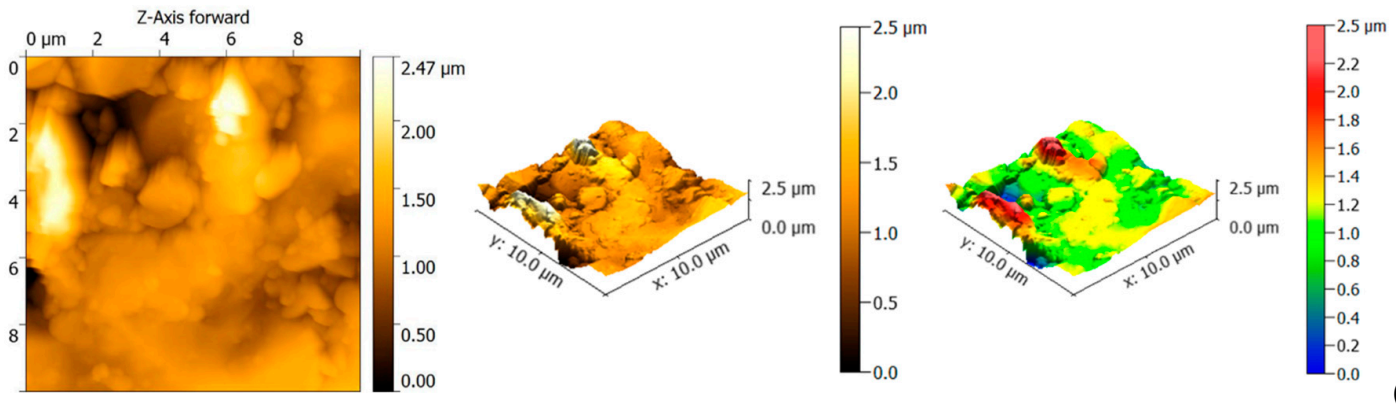

(b)

Figure 5. Representative 2D and 3D atomic force microscopy (AFM) images for EPNCs with DDM: (a) control sample (CS); (b) $5 \mathrm{wt}$. (\%) sample.
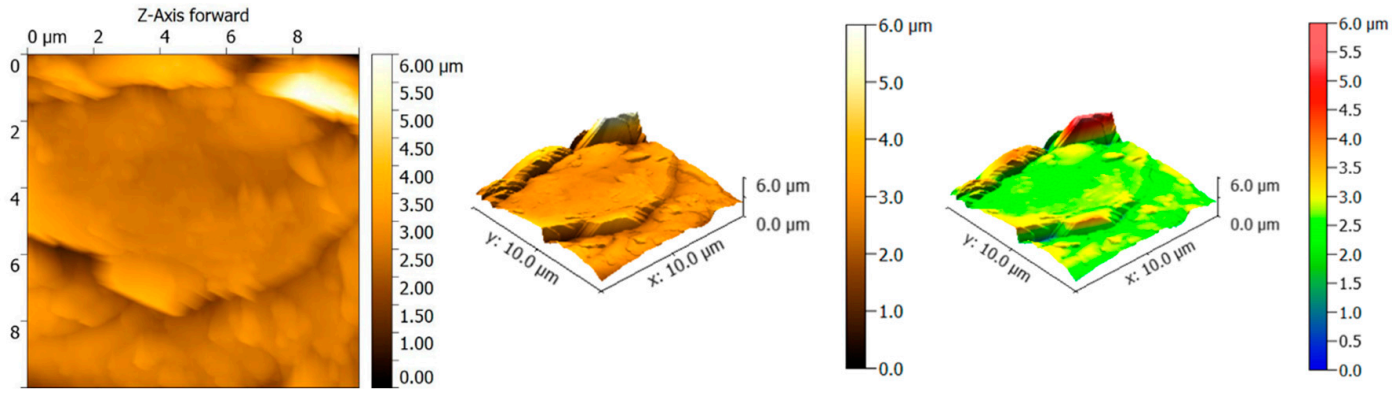

(a)
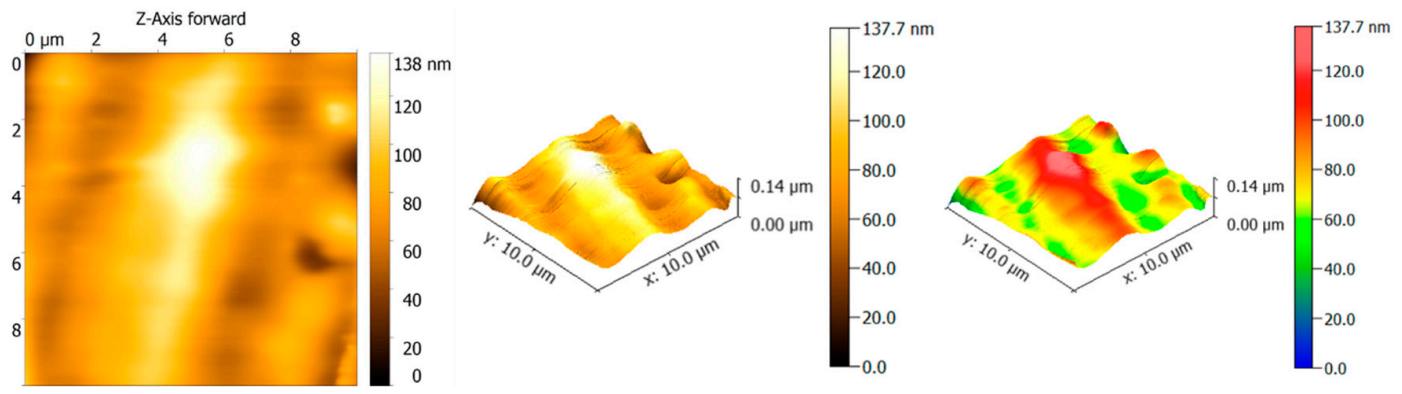

(b)

Figure 6. Representative 2D and 3D AFM images for EPNCs with DDSA+MNA: (a) CS; (b) 3 wt. (\%) sample.

Figure 7 illustrates the comparison between the roughness $\left(R_{a}\right)$ and the CA $\left(\theta^{*}\right)$. From the figure, it is possible to conclude that in the case of EPNCs with DDM hardener, the wettability is improved for the more hydrophilic surfaces with the increase in roughness. For EPNCs with DDSA+MNA hardener, the lower value of the roughness corresponds to the higher value of CA. These results are in agreement with Syakur et al. [40], verifying that the surface hydrophobicity of epoxy resin is influenced by the 
chemical surface of components. Also, Kubiak et al. [42] observed that the roughness had a strong influence on the wettability of engineering surfaces.

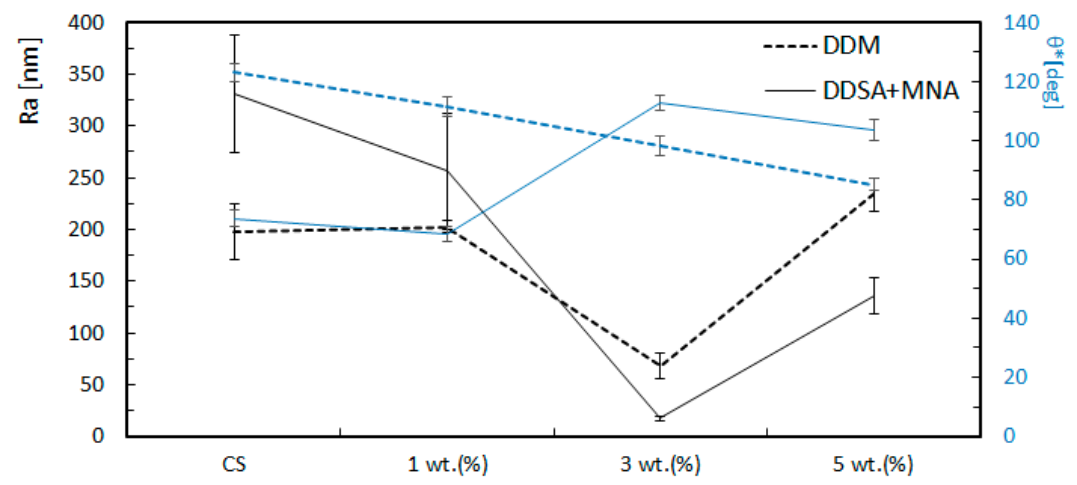

Figure 7. Roughness versus contact angle.

In fact, it was expected that as the roughness increases, the CA should also increase. This can be explained by the "lotus effect", whereby lotus leaves repel water because of the presence of small bumps at the micro- and nanometer scale on the surface [43]. In this case, a drop of water is supported between the peaks of the protuberances, which is the shortest contact, therefore acquiring a more spherical shape (that is, with a higher CA). The observed different behavior for the tested samples can be explained by the curing agents and manufacturing procedures used. In fact, in the case of DDSA+MNA, a postcuring cycle was performed to manufacture the EPNCS, while for the case of DDM the EPNCs, these were not subjected to postcuring. According to Amaro et al. [2], the degree of enhancement of a specific property is highly dependent on the type of curing agent used, and also on the state of the dispersion of the NPs throughout the EP resin matrix.

In previous studies, a correlation between the mesoscopic structure and wettability has been reported for bionanocomposite films [44,45]. In particular, it was observed that the inclusion of nanotubes into the studied composite films led to a significant decrease of the CA. The authors explained this observation as being due to the presence of hydrophilic nanotubes on the film surface. In this study, functionalized alumina NPs with APTES were used (Section 2.1). Hence, amine groups exist at the surface of the NPs, which make them hydrophilic. From this point of view, the results in this study should also show a general decrease of the CA due to the inclusion of the alumina NPs in the EP matrix. This is observed for EPNCs with DDM, but not in general for EPNCs with DDSA+MNA (Figure 7). As previously mentioned, these differences can be explained by the curing agents and manufacturing procedures used.

\section{Conclusions}

This work studied the surface properties (namely the wettability and roughness) of EPNCs manufactured with different curing agents (DDM and DDSA+MNA) and reinforced with alumina NPs. The weight fractions of alumina NPs were 1, 3, and $5 \mathrm{wt} .(\%)$.

From the obtained results, it was concluded that the CA decreases as the weight fraction of alumina NPs increases in the case of EPNCs with DDM as the curing agent, presenting hydrophobic behavior $\left(90^{\circ}<\theta^{*}<120^{\circ}\right)$ until 3 wt. (\%) and hydrophilic behavior $\left(\theta^{*}<90^{\circ}\right)$ for the 5 wt. $(\%)$ sample. For EPNCs with DDSA+MNA as the hardener, complex behavior is achieved and the addition of alumina NPs promotes a decrease in CA in the CS until 1 wt. (\%), with both being hydrophilic, followed by an increase of CA for $3 \mathrm{wt}$. (\%) NPs and a small decrease for $5 \mathrm{wt}$. (\%) NPs. For the two last NP loadings, the EPNCs were shown to be hydrophobic. The higher loading of alumina NPs (5 wt. (\%)) were shown to have a negative effect on the hydrophobicity for EPNCs with DDM as the hardener, which became hydrophilic. 
A decrease in the roughness for EPNCs with both hardeners was achieved from CS until 3 wt. (\%), followed by an increase for $5 \mathrm{wt}$. (\%). In the case of EPNCs with DDM, the higher roughness was observed for $5 \mathrm{wt}$. (\%), while for EPNCs with DDSA+MNA, the higher roughness was observed for CS. The results for the average measured roughness did not show the same tendency as for the contact angle, as was expected. It may be necessary to ensure the homogeneity of the sample surfaces of EPNCs before testing, for instance by selecting the right polishing technique.

Author Contributions: D.P. designed and conducted experiments (contact angles, AFM images, and data processing), and contributed to the discussion of results. A.M.A. analyzed and interpreted results and wrote the manuscript. L.B. interpreted the results and wrote the manuscript. All authors have read and agreed to the published version of the manuscript.

Funding: This research received no external funding.

Acknowledgments: The authors acknowledge the Programa de Cooperación Territorial INTERREG V-A MAC 2014-2020 and Proyecto Ecofibras (MAC/4.6d/040); the partial support of Fundação para a Ciência e a Tecnologia (FCT) (Project PEst-OE/QUI/UI0674/2019, CQM, Portuguese government funds) and Agência Regional para o Desenvolvimento da Investigação Tecnologia e Inovação (ARDITI) through the project M1420-01-0145-FEDER-000005-CQM + (Madeira 14-20 Program); and to the project UID/EMS/00285/2019.This research is sponsored by the project UID/EMS/00285/2019. The authors also greatly appreciate Rita Castro's help and support in the AFM analysis.

Conflicts of Interest: The authors declare no conflict of interest.

\section{References}

1. Amaro, A.M.; Bernardo, L.; Pinto, D.G.; Lopes, S.; Rodrigues, J.; Louro, C.S. Effect of irregular shaped nanoalumina on the enhancement of mechanical properties of epoxy resin nanocomposites using DDM as hardener. Compos. Part B Eng. 2016, 84, 17-24. [CrossRef]

2. Amaro, A.M.; Bernardo, L.; Pinto, D.G.; Lopes, S.; Rodrigues, J. The influence of curing agents in the impact properties of epoxy resin nanocomposites. Compos. Struct. 2017, 174, 26-32. [CrossRef]

3. Wetzel, B.; Rosso, P.; Haupert, F.; Friedrich, K. Epoxy nanocomposites-Fracture and toughening mechanisms. Eng. Fract. Mech. 2006, 73, 2375-2398. [CrossRef]

4. Zhang, H.; Zhang, H.; Tang, L.; Liu, G.; Zhang, D. The Effects of Alumina Nanofillers on Mechanical Properties of High-Performance Epoxy Resin. J. Nanosci. Nanotechnol. 2010, 10, 7526-7532. [CrossRef] [PubMed]

5. Argon, A.S.; Cohen, R.E. Toughenability of polymers. Polymer 2003, 44, 6013-6032. [CrossRef]

6. Jagtap, R.; Ambre, A. Atomic force microscopy (AFM): Basics and its important applications for polymer characterization: An overview. J. Polym. Mater. 2005, 22, 1-26.

7. Pinto, D.; Bernardo, L.; Amaro, A.; Lopes, S. Mechanical properties of epoxy nanocomposites using titanium dioxide as reinforcement-A review. Constr. Build. Mater. 2015, 95, 506-524. [CrossRef]

8. Pinto, D.; Bernardo, L.; Amaro, A.; Lopes, S. Mechanical properties of epoxy nanocomposites using alumina as reinforcement-A review. J. Nano Res. 2015, 30, 9-38. [CrossRef]

9. Day, R.J.; Lovell, P.A.; Wazzan, A.A. Toughened carbon/epoxy composites made by using core/shell particles. Compos. Sci. Technol. 2001, 61, 41-56. [CrossRef]

10. Kinloch, A.J.; Maxwell, D.L.; Young, R.J. The fracture of hybrid-particulate composites. J. Mater. Sci. 1985, 20, 4169-4184. [CrossRef]

11. Maxwell, D.; Young, R.J.; Kinloch, A.J. Hybrid particulate-filled epoxy-polymers. J. Mater. Sci. Lett. 1984, 3, 9-12. [CrossRef]

12. Zhang, H.; Zhang, Z.; Friedrich, K.; Eger, C. Property improvements of in situ epoxy nanocomposites with reduced interparticle distance at high nanosilica content. Acta Mater. 2006, 54, 1833-1842. [CrossRef]

13. Zhang, H.; Tang, L.C.; Zhang, Z.; Friedrich, K.; Sprenger, S. Fracture behaviours of in situ silica nanoparticle-filled epoxy at different temperatures. Polymer 2008, 49, 3816-3825. [CrossRef]

14. Johnsen, B.B.; Kinloch, A.J.; Mohammed, R.D.; Taylor, A.C.; Sprenger, S. Toughening mechanisms of nanoparticle-modified epoxy polymers. Polymer 2007, 48, 530-541. [CrossRef]

15. Bittmann, B.; Englert, M.; Haupert, F.; Schlarb, A.K. Influence of the insertion of TiO2-nanoparticles in epoxy resins on the curing behavior and the resulting mechanical properties. J. Adv. Mater. 2009, 41, $20-27$. 
16. Zhang, Z.; Breidt, C.; Chang, L.; Haupert, F.; Friedrich, K. Enhancement of the wear resistance of epoxy: Short carbo fibre, graphite, PTFE and nano-TiO2. Compos. Part A Appl. Sci. Manuf. 2004, 35, 1385-1392. [CrossRef]

17. Zunjarrao, S.C.; Singh, R.P. Characterization of the fracture behavior of epoxy reinforced with nanometer and micrometer sized aluminum particles. Compos. Sci. Technol. 2006, 66, 2296-2305. [CrossRef]

18. Naous, W.; Yu, X.Y.; Zhang, Q.X.; Naito, K.; Kagawa, Y. Morphology, Tensile Properties, and Fracture Toughness of Epoxy $/ \mathrm{Al}_{2} \mathrm{O}_{3}$ Nanocomposites. J. Polym. Sci. Part B Polym. Phys. 2006, 44, 1466-1473. [CrossRef]

19. Zhao, S.; Schadler, L.S.; Duncan, R.; Hillborg, H.; Auletta, T. Mechanisms leading to improved mechanical performance in nanoscale alumina filled epoxy. Compos. Sci. Technol. 2008, 68, 2965-2975. [CrossRef]

20. Zalikha, N.Z.; Feisal, M.F.; Ishak, M. Influence of Al2O3 nanoreinforcement on the adhesion and thermomechanical properties for epoxy adhesive. Compos. Part B Eng. 2019, 172, 9-15.

21. Hill, D.; Barron, A.R.; Alexander, S. Comparison of hydrophobicity and durability of functionalized aluminium oxide nanoparticle coatings with magnetite nanoparticles_Links between morphology and wettability. J. Colloid Interface Sci. 2019, 555, 323-330. [CrossRef] [PubMed]

22. Lim, S.H.; Zeng, K.Y.; He, C.B. Morphology, tensile and fracture characteristics of epoxy-alumina nanocomposites. Mater. Sci. Eng. 2010, 527, 5670-5676. [CrossRef]

23. Wetzel, F.; Haupert, M.; Zhang, M.Q. Epoxy nanocomposites with high mechanical and tribological performance. Compos. Sci. Technol. 2003, 63, 2055-2067. [CrossRef]

24. Shukla, D.K.; Parameswaran, V. Epoxy composites with $200 \mathrm{~nm}$ thick alumina platelets as reinforcements. J. Mater. Sci. 2007, 42, 5964-5972. [CrossRef]

25. Chozhan, C.K.; Chandramohan, A.; Alagar, M. Influence of Multi-Walled Carbon Nanotubes on Mechanical, Thermal and Electrical Behavior of Polybenzoxazine-Epoxy Nanocomposites. Polym. Plast. Technol. Eng. 2015, 54, 68-80. [CrossRef]

26. George, S.M.; Puglia, D.; Kenny, J.M.; Parameswaranpillai, J.; Thomas, S. Reaction-Induced Phase Separation and Thermomechanical Properties in Epoxidized Styrene-block-butadiene-block-styrene Triblock Copolymer Modified Epoxy/DDM System. Ind. Eng. Chem. Res. 2014, 53, 6941-6950. [CrossRef]

27. Mandhakini, M.; Lakshmikandhan, T.; Chandramohan, A.; Alagar, M. Effect of Nanoalumina on the Tribology Performance of C4-Ether-Linked Bismaleimide-Toughened Epoxy Nanocomposites. Tribol. Lett. 2014, 54, 67-79. [CrossRef]

28. Amaro, A.M.; Pinto, D.G.; Bernardo, L.; Lopes, S.; Rodrigues, J.; Louro, C.S. Mechanical Properties of Alumina Nanofilled Polymeric Composites Cured with DDSA and MNA. Fibers Polym. 2018, 19, 460-470. [CrossRef]

29. Gupta, S.K.; Shukla, D.K.; Ravindra, D.K. Effect of nanoalumina in epoxy adhesive on lap shear strength and fracture toughness of aluminium joints. J. Adhes. 2019, 1-23. [CrossRef]

30. de Morais, A.B.; Pereira, A.B.; Teixeira, J.P.; Cavaleiro, N.C. Strength of epoxy adhesive-bonded stainless-steel joints. Int. J. Adhes. Adhes. 2007, 27, 679-686. [CrossRef]

31. Chang, L.; Zhang, Z.; Breidt, C.; Friedrich, K. Tribological properties of epoxy nanocomposites. I. Enhancement of the wear resistance by nano-TiO2 particles. Wear 2005, 258, 141-148. [CrossRef]

32. Maghsoudian, A.; Salimi, A.; Mirzataheri, M. The effect of nanoalumina silanisation in tetraglycidylether epoxy adhesive. Int. J. Adhes. Adhes. 2019, 92, 119-124. [CrossRef]

33. Bardella, L. Mechanical Behavior of Glass-Filled Epoxy Resins: Experiments, Homogenization Methods for Syntactic Foams, and Applications. Ph.D. Thesis, University of Brescia, Brescia, Italy, 2000; p. 294.

34. Belleri, L.B.A. Two features of the uniaxial compression of a glassy epoxy resin: The yield stress rate-dependence and the volumetric instability. Mech. Time Depend. Mater. 2011, 15, 255-275.

35. Martinet, W.; Van den Plas, D.; Raes, H.; Reekmans, R.; Contreras, R. Bax-induced cell death in Pichia pastoris. Biotechnol. Lett. 1999, 21, 821-829. [CrossRef]

36. Krüss-Scientific. 2020. Available online: https://www.kruss-scientific.com/products/drop-shape/dsa100/ drop-shape-analyzer-dsa100/ (accessed on 3 January 2020).

37. Biolin Scientific. 2020. Available online: https://cdn2.hubspot.net/hubfs/516902/Pdf/Attension/Tech\%20Notes/ AT-TN-07-Surface-roughness-CA-wettability.pdf (accessed on 3 January 2020).

38. Tanaka, T.; Lee, J.; Scheller, P.R. Chapter 1.5-Interfacial free energy and wettability. In Treatise on Process Metallurgy, Process Phenomena; Elsevier: Amsterdam, The Netherlands, 2014; Volume 2, pp. 61-77. 
39. Radiom, M.; Yang, C.; Chan, W.K. Characterization of surface tension and contact angle of nanofluids. In Proceedings of the Fourth International Conference on Experimental Mechanics, Singapore, 14 April 2010. [CrossRef]

40. Syakur, A.; Sutanto, H. Determination of Hydrophobic Contact Angle of Epoxy Resin Compound Silicon Rubber and Silica. In IOP Conference Series: Materials Science and Engineering; IOP Publishing: Bristol, UK, 2017; Volume 170, p. 012025. [CrossRef]

41. Uelzen, T.H.; Muller, J. Wettability enhancement by rough surfaces generated by thin film technology. Thin Solid Film. 2003, 434, 311-315. [CrossRef]

42. Kubiak, K.J.; Wilson, M.C.T.; Mathia, T.G.; Carval, P.H. Wettability versus roughness of engineering surfaces. Wear 2011, 271, 523-528. [CrossRef]

43. Lafuma, A.; Quéré, D. Superhydrophobic states. Nat. Mater. 2003, 2, 457-460. [CrossRef]

44. Bertolino, V.; Cavallaro, G.; Lazzara, G.; Milioto, S.; Parisi, F. Halloysite nanotubes sandwiched between chitosan layers: Novel bionanocomposites with multilayer structures. New J. Chem. 2018, 42, 8384-8390. [CrossRef]

45. Makaremi, M.; Pasbakhsh, P.; Cavallaro, G.; Lazzara, G.; Kit Aw, Y.; Mae Lee, S.; Milioto, S. Effect of Morphology and Size of Halloysite Nanotubes on Functional Pectin Bionanocomposites for Food Packaging Applications. ACS Appl. Mater. Interfaces 2017, 9, 17476-17488. [CrossRef]

(C) 2020 by the authors. Licensee MDPI, Basel, Switzerland. This article is an open access article distributed under the terms and conditions of the Creative Commons Attribution (CC BY) license (http://creativecommons.org/licenses/by/4.0/). 